\title{
IMOVINA I ODGOVORNOST ZA OBAVEZE PREDUZETNIKA
}

\author{
Velisav Marković \\ Univerzitet Singidunum, Poslovni fakultet u Valjevu, Železnička 5, Valjevo, Srbija
}

\section{Apstrakt:}

Preduzetnik je poslovno sposobno fizičko lice koje obavlja svoje delatnosti u cilju ostvarivanja prihoda i kao takvo je registrovano u skladu sa zakonom o registraciji. Zakonom o privrednim društvima nije regulisano šta čini imovinu preduzetnika. Pojam imovine uređen je građansko-pravnim propisima. Imovina je skup svih subjektivnih imovinskih prava jednog lica. Predmet imovine su: stvarna prava, intelektualna imovinska prava (autorska prava i prava industrijske svojine), prava ličnosti (ako su izražena u imovinskom vidu) i obligaciona prava (izuzev onih koja se ne mogu novčano izraziti). Za sve obaveze nastale u vezi sa obavljanjem svoje delatnosti preduzetnik odgovara celokupnom svojom imovinom, i u tu imovinu ulazi i imovina koju stiče u vezi sa obavljanjem tih delatnosti. Odgovornost za obaveze nastale u vezi sa obavljanjem delatnosti je lična, neposredna i neograničena, bez mogućnosti njenog ograničenja, i ista ne prestaje brisanjem preduzetnika iz registra. U praksi se kao sporno pitanje nameće pitanje odgovornosti supružnika za obaveze preduzetnika, odgovornosti članova porodičnog domaćinstva, u slučaju promene pravne forme u privredno društvo, u slučaju smrti ili gubitka poslovne sposobnosti. Oslanjajući se na teoriju i sudsku praksu kao na i uporedno-pravna rešenja, autor ispituje ličnu odgovornost preduzetnika kao i odgovornost supružnika i članova porodičnog domaćinstva za obaveze preduzetnika, odgovornost preduzetnika u slučaju promene pravne forme, kao i odgovornost naslednika u slučaju smrti preduzetnika ili lišenja poslovne sposobnosti radi rasvetljavanja spornih situacija.
\end{abstract}

\section{Ključne reči:}

preduzetnik,

imovina preduzetnika,

odgovornost za obaveze.

\section{POJAM I PRAVNI POLOŽAJ PREDUZETNIKA}

Preduzetnik (trgovac) je pravna forma organizovanja preduzeća radi obavljanja određene delatnosti radi sticanja dobiti, pod, po pravilu individualnim (ličnim) poslovnim imenom od strane fizičkog lica i sa neograničenom odgovornošću celom svojom imovinom. Individualni trgovac - preduzetnik dakle, može isključivo biti fizičko lice (koje ima poslovnu sposobnost) i nikako pravno lice (Vasiljević, 2008).

Individualni preduzetnik je poslovni oblik koji osniva i organizuje jedna osoba. To je najprostiji pravni oblik da se osnuje, a takođe i najkorišćenija forma malih privrednih subjekata (Cohen, 2006).

Indivdualni preduzetnik je popularna poslovna forma zbog svoje jednostavnosti, jednostavnog otvaranja i normalnog troška. Pojedincu treba samo registracija i odgovarajuća lokalna licenca i isti je spreman za posao (Spadaccini, 2007).

Individualni preduzetnik (eng. Sole proprietorship) je nekorporativno poslovanje koje je vođeno od jedne osobe kao samostalna delatnost. Samostalni preduzetnik (privatnik) koji obavlja slobodnu profesiju (poziv računovođe ili advokata) poznat je kao samostalni vršilac slobodne profesije. Takođe, vršilac slobodne profesije je u poslovanju poznat kao individualni trgovac (sole trader) (Clark, 2001).

U nemačkom pravu za preduzetnika se koristi termin „,trgovac" ili „registrovani trgovac“ (eingetragener Kaufman EK, E.KFM ili ženski oblik e.Kfr, (CRG)). Ukoliko preduzetnik dostigne godišnji promet od 250.000 evra mora da izvrši upis u Trgovinski registar. Ako ima manji godišnji promet upis u registar je dobrovoljan. Nemački trgovinski zakon (HGB) se primenjuje na registrovanog trgovca (CCEMR).

U Švajcarskoj se za preduzetnika koristi termin „Einzelunternehmen " $i$ to je fizičko lice koje obavlja poslovnu delatnost u svoje ime i svoju odgovornost. Isti snosi punu neograničenu odgovornost za obaveze uključujući i privatnu imovinu. Preduzetnik je u Švajcarskoj često prvi korak u samozapošljavanju. Poslovno ime preduzetnika mora da sadrži prezime vlasnika kao glavnu komponentu. Preduzetnik mora biti registrovan u privrednom registru ako ima godišnji promet od $100.000 \mathrm{CHF}$ a ako je promet manji registracija je dobrovljna. U svakom slučaju preduzetniku mora da se prizna status samozaposlenog. Socijalno osiguranje smatra da je fizičko lice samzaposleno ako radi u svoje ime i za svoj račun, ima nezavisnu poziciju, nosi sopstveni ekonomski rizik. Priznavanjem samozapošljavanja bavi se Kancelarija socijalnog osiguranja u Cirihu (Grüenden).

Pravni položaj preduzetnika u našem pravu uređen je Zakonom o privrednim društvima (Sl. glasnik RS, broj 36/2011, 99/2011, 83/2014, 5/2015, u daljem tekstu: ZPD). Prema članu 83. ZPD preduzetnik je poslovno sposobno fizičko lice koje obavlja delatnost u cilju ostvarvanja prihoda i koje je kao takvo registrovano u skladu sa zakonom o registraciji. Preduzetnik ne može biti pravno lice.

$\mathrm{Za}$ obavljanje samostalne delatnosti, preduzetnik osniva radnju, odnosno odgovarajući oblik poslovanja (radionica, 
kancelarija, biro, servis, agencija, studio, pansion, apoteka, ordinacija i sl.).

Da bi fizičko lice bilo preduzetnik potrebno je da budu ispunjeni zakonski uslovi:

1) da je to fizičko lice poslovo sposobno,

2) da to fizičko lice obavlja određenu delatnost,

3) da tu delatnost obavlja u cilju ostvarivanja prihoda i

4) da je registrovano u skladu sa zakonom o registraciji.

Fizičko lice upisano u posebni registar, koje obavlja delatnost slobodne profesije uređenu posebnim propisima, smatra se preduzetnikom u smislu Zakona o privrednim društvima ako je tim propisima to određeno. Slobodna profesija je ona profesija koja je kao takva kvalifikovana i definisana zakonom - advokatura, notarijat, zdravstvo, inženjerstvo, revizija, poresko savetovanje, aktuarstvo, umetnost, novinarstvo, veterinarstvo i dr. ${ }^{1}$

Individualni poljoprivrednik nije preduzetnik u smislu ovog zakona, osim ako posebnim zakonom nije drukčije uređeno. Isti stiče status preduzetnika i ima obavezu vođenja poslovnh knjiga:

a) ako se nosilac registrovanog poljoprivrednog gazdinstva (dobrovoljno) opredelio da ima svojstvo preduzetnika podnošenjem poreske prijave nadležnom poreskom organu,

b) ako je registrovano poljoprivredno gazdinstvo obveznik poreza na dodatu vrednost (PDV).

Međutim, preduzetnik upisom u Registar privrednih subjekata ne stiče svojstvo pravnog lica već zadržava svojstvo fizičkog lica. Upisom u registar preduzetnik stiče svojstvo privrednog subjekta i pojedina svojstva pravnog lica. ${ }^{2}$ Elementi pravnog subjektiviteta pravnog lica koje ima preduzetnik su: poslovno ime, sedište, delatnost i dr. (Carić, Vitez, Veselinović, 2006).

\section{IMOVINA PREDUZETNIKA}

Zakonom o privrednim društvima nije regulisano šta čini imovinu preduzetnika. Pojam imovine uređen je građanskopravnim propisima.

Imovina je skup svih subjektivnih imovinskih prava jednog lica. Predmet imovine su: stvarna prava, intelektualna imovinska prava (autorska prava i prava industrijske svojine), prava ličnosti (ako su izrajžena u imovinskom vidu) i obligaciona prava (izuzev onih koja se ne mogu uopšte novčano izraziti).

Svaki pravni subjekt ima jednu imovinu, a ona je, po pravilu, nerazdvojna od njega (Paund, 2000).

Objekti imovinskog prava mogu biti: stvar, radnje, lična dobra i intelektualna dobra. Povodom ovih objekata pravni subjekti su u imovinsko-pravnom odnosu.

1 Na primer, u Kodeksu profesionalne etike advokata „Advokatura je profesionalno obavljanje advokatske delatnosti“, (Kodeks profesionalne etike advokata "Službeni glasnik RS", br. 27/2012 član 3. tačka 3.1.1.). Više o slobodnim profesijama (Dabić, 2008).

2 „Stranka u postupku koji nastane u vezi sa poslovanjem i delatnošću radnje može biti samo fizičko lice kao vlasnik odnosno osnivač te radnje, a ne i sama radnja budući da radnja nema status pravnog lica već pojedina svojstva pravnog lica. Kako radnja nema sopstven pravni subjektivitet, ona ne može biti nosilac prava i obaveza, pa time ne može biti ni stranka u postupku." Iz rešenja Okružnog suda u Novom Sadu, Gž. 1055/05 od 11.05.2006. godine, Bilten sudske prakse Okružnog suda u Novom Sadu broj 9/2006. Tako i „Stranka u postupku može biti fizičko lice, kao preduzetnik i vlasnik radnje, ali ne može biti radnja." Iz rešenja Vrhovnog suda Srbije, Prev. 34/01 i Pzz. 2/01 od 07.02.2001. godine, Pravo i privreda broj 1-4/2002, str. 236.
Stvar je materijalni deo prirode u ljudskoj vlasti na kome postoji subjektivno imovinsko pravo. Materijalni deo prirode, određen kao stvar, mora ispunjavati fizičke i pravne pretpostavke. Fizička pretpostavka znači da deo prirode može biti u vlasti čoveka, a pravna pretpostavka zahteva da se na tom delu materijlane prirode može steći stvarno pravo ili neko drugo subjektivno imovinsko pravo.

Radnje su aktivna ili neaktivna ljudska ponašanja na koja je dužnik obavezan poveriocu na osnovu nekog obligacionog odnosa. Mogu se sastojati u davanju, činjenju, nečinjenju ili trpljenju. Radnje su objekat obligacionih odnosa, dok su stvar objekat stvarnopravnih odnosa.

Lična prava su prava imaoca na ličnim dobrima, kao što su: pravo na život, zdravlje, slobodu, čast, ugled, telesni, duhovni i moralni integritet, identitet, privatnost, ime, lik, glas. Ova prava se jednim delom štite imovinskim pravom i to samo ako se mogu izraziti u imovinskom vidu.

Intelektualna prava su tvorevine ljudskog uma koje za svoj predmet imaju autorska i pravo industrijske svojine (patent, uzorak, model, žig, geografsko poreklo i dr.). Ova prava pored moralne imaju i imovinskopravnu komponentu (pravo na iskorišćavanje dela ili pronalaska) (Marković, 2014).

Imovinsko-pravni odnos je odnos između titulara subjektivnog imovinskog prava i lica prema kojima su uperena ta ovlašćenja, odnosno obaveznih lica. Imovinskopravni odnos obuhvata ovlašćenu stranu (titulara prava) i lica prema kome su uperena ovlašćenja titulara subjektivnog prava, odnosno obaveznog lica. Tako, vlasnik automobila, ima subjektivno stvarno pravo iz koga proističe obaveza držanja, upotrebe i raspolaganja tom stvari. Pravo svojine nameće dužnosti svih ostalih lica. Obligacioni odnos nastaje između poverioca i dužnika. Poverilac je ovlašćen zahtevati od dužnika ispunjenje obaveze, a dužnik je dužan ispuniti obavezu u svemu kako ona glasi (Babić, 2011).

\section{ODGOVORNOST PREDUZETNIKA}

Preduzetnik za sve obaveze nastale u vezi sa obavljanjem svoje delatnosti odgovara celokupnom svojom imovinom i u tu imovinu ulazi i imovina koju stiče u vezi sa obavljanjem delatnosti. $^{3}$

Tako i u uporednom pravu: preduzetnik je lično odgovoran za sve poslovne gubitke i mora da ima u punoj meri dostupne lične resurse. Vlasnik je lično odgovoran za sve obaveze iz poslovanja. Suprotno od akcionara ili ograničenog partnera, vlasnik brine o finansijskom riziku koji je neograničen za njegovu investiciju u firmu/radnju, uključujući sva lična sredstva, kuću, kola, garnituru i sličnu imovinu (Moye, 2004).

Vlasnik je neodvojiv od preduzetnika (kao oblika poslovanja) tako da je odgovoran za bilo koje poslovne dugove (Masoom, 2013).

Odgovornost za obaveze nastale u vezi sa obavljanjem delatnosti je lična, neposredna i neograničena, bez mogućnosti njenog ograničenja.

Odgovornost za navedene obaveze ne prestaje brisanjem preduzetnika iz registra.

3 "U imovinu fizičkog lica koje je preduzetnik ulaze prava, potraživanja i sredstva ostvarena kroz delatnost za koju je radnja registrovana, ali i prava, potraživanja i sredstva ostvarena izvan nje, iz drugih materijalno pravnih odnosa. Imovinu tog lica opterećuju i obaveze koje je ono preuzelo u vezi sa obavljanjem registrovane delatnosti, ali i obaveze koje su preuzete izvan nje." Iz rešenja Višeg trgovinskog suda, Pž. 9249/07 od 03.04.2008. godine, Sudska praksa trgovinskih sudova - Bilten broj 2/2008. 
Činjenica brisanja preduzetnika iz registra privrednih subjekata nije pravno relevantna za odgovornost po osnovu nastalih imovinskih obaveza u vezi sa obavljanjem delatnosti fizičkog lica koje je bilo registrovano kao preduzetnk. Preduzetnik nema svojstvo pravnog lica. Stranačku i pravnu sposobnost ima fizičko lice koje je registrovano kao preduzetnik. Stoga, brisanjem preduzetnika i na taj način prestankom svojstva preduzetnika, ne prestaje odgovornost fizičkog lica koje je bilo registrovano kao preduzetnik za nastale obaveze. ${ }^{4}$

Kako odgovornost preduzetnika za sve obaveze nastale u vezi sa obavljanjem delatnosti ne prestaju sa brisanjem preduzetnika iz registra privrednih subjekata, može se postaviti pitanje kada te obaveze preduzetnika prestaju? Odgovor na ovo pitanje je da odgovornost za obaveze preduzetnika prestaju kada preduzetnik izvrši svoje obaveze ili kada nastupi neki drugi zakonski razlog za prestanak obaveza (poravnanje, kompenzacija, otpuštanje duga, novacija, sjedinjenje, nemogućnošću ispunjenja, zastarelošću i dr.) (Babić, 2008).

Ipak naš pravni sistem nije dosledno sproveo princip jedinstva imovine preduzetnika. Kada se sprovodi prinudno izvršenje na imovini preduzetnika blokadom tekućeg računa, izvršenje se sprovodi samo na tekućim računima koji pripadaju preduzetniku, odnosno tekućim računima koje je on otvorio radi obavljanja delatnosti u statusu preduzetnika. Ovi računi se identifikuju preko matičnog broja i PIB-a, što ne omogućava identifikaciju njegovih ličnih računa koji ne služe obavljanju delatnosti. Moguće je da se prinudno izvršenje zahteva i na privatnim računima preduzetnika - na onima koje on koristi kao fizičko lice, a ne radi obavljanja delatnosti, ali se ti računi neće identifikovati u postupku prinudnog izvršenja i neće biti blokirani, ako je prinudno izvršenje traženo samo na računima koji se identifikuju peko matičnog broja i PIB -a preduzetnka.

Zakon o obavljanju plaćanja pravnih lica, preduzetnika i fizičkih lica koja ne obavljaju delatnost (Sl. glasnik RS, broj 68/2015) u članu 5. stav 2. sadrži zabrane kojima je predviđeno da pravna lica i preduzetnici ne mogu izmirivati svoje obaveze ugovaranjem promene poverioca ili dužnika (asignacija, cesija, pristupanje dugu, preuzimanje duga, ustupanje duga i dr.), kompenzacijom ili na drugi način, ako su im tekući računi blokirani. Ovo važi i za preduzetnike, ali ne i za njegove obaveze koje nisu nastale obavljanjem delatnosti. Čak i da je njegov lični tekući račun blokiran, za njega ne važi zabrana zaključivanja pomenutih ugovora, ako ih zaključuje kao fizičko lice, a ne kao privredni subjekt, odnosno preduzetnik, ako nije reč o obavezama koje su nastale obavljanjem delatnosti kao preduzetnika. Jedinstvo imovine omogućava da prava i obaveze stečene obavljanjem delatnosti nadživljuju sam status preduzetnika. Činjenica da je preduzetnik brisan iz registra ne utiče na stečena prava i obaveze za vreme dok je on taj status imao. Prestanak statusa preduzetnka ne dovodi do bilo kakve sukcesije jer su prava i obaveze već zasnovani u korist lica koje je imalo status preduzetnika. Ovo važi za imovinska prava i obaveze za koje se ne zahteva nikakva posebna dozvola (odobrenje, saglasnost) za obavljanje delatnosti. Međutim, ako je reč o pravima ili obavezama koji se mogu zasnovati samo u korist (na teret) lica koje ima određenu dozvolu za obavljanje delatnosti i ako

4 Vidi rešenje Privrednog apelacionog suda, Pž. 424/2012 od 19.09.2012. godine, tako i „Brisanjem iz registra samostalne preduzetničke radnje, ne prestaje punomoćje koje je fizičko lice - preduzetnik dalo advokatu." Iz rešenja Privrednog apelacionog suda Pž. 893/2013 od 21.02.2013. godine, ParagrafLex je reč o nenovčanoj obavezi koja se može ispuniti samo ako za to postoji dozvola, gubitkom statusa preduzetnika, fizičko lice koje više nije registrovano za obavljanje delatnosti nema pravo da ispuni takve obaveze, ali može odgovarati za naknadu štete. Za razliku od ovakvih nenovčanih obaveza koje se preuzimaju samo na osnovu dozvole, ako je reč o nenovčanim obavezama za koje nije potrebna dozvola ili o novčanim obavezama, gubitak statusa preduzetnika ne utiče na njihovo postojanje i obavezu ispunjenja (Stefanović, 2014).

U praksi se može postaviti i pitanje odgovornosti supružnika preduzetnika ukoliko se njihovo zajedničko porodično domaćinstvo izdržavalo od prihoda ostvarenih obavljanjem delatnosti preduzetnika. S tim u vezi, sudska praksa je zauzela stav: „Supružnici solidarno odgovaraju za pozajmicu koja je data jednom od supružnika, koji je istupao u svojstvu preduzetnika, ukoliko se njihovo zajedničko domaćinstvo izdržavalo od prihoda ostvarenih preduzetničkom delatnošću. "

Posebno je uređena odgovornost članova domaćinstva za poreske obaveze preduzetnika. Naime, za porez na prihode od samostalne delatnosti jemče supsidijarno svojom imovinom svi punoletni članovi domaćinstva obveznika koji u momentu nastanka obaveze čine domaćinstvo obveznika.

Takođe, lice koje sa ili bez naknade preuzme deo ili celokupnu imovinu kojom preduzetnik obavlja delatnost jemči solidarno za obaveze preduzetnika nastale obavljanjem delatnosti pre preuzimanja imovine do visine vrednosti preuzete imovine, a preduzetnik koji prestaje da obavlja delatnost dužan je da pre brisanja iz propisanog registra izmiri sve svoje poreske obaveze nastale tokom obavljanja delatnosti (član 157. stav 2. i 3. Zakona o porezu na dohodak građana).

Može se postaviti pitanje odgovornosti naslednika za obaveze preduzetnika u slučaju njegove smrti ili gubitka poslovne sposobnosti. Članom 91. stav 7. ZPD propisano je da u slučaju smrti ili gubitka poslovne sposobnosti preduzetnika, naslednik odnosno član njegovog porodičnog domaćinstva (bračni drug, deca, usvojenici i roditelji) koje je pri tom i sam poslovno sposobno fizičko lice, može nastaviti obavljanje delatnosti na osnovu rešenja o nasleđivanju ili međusobnog sporazuma o nastavku obavljanja delatnosti, koji potpisuju svi naslednici, odnosno članovi porodičnog domaćinstva. Lice koje nastavlja delatnost u svojstvu preduzetnika dužno je da u roku od 30 dana od dana smrti preduzetnika prijavi nastavak obavljanja delatnosti registru u skladu sa zakonom o registraciji privrednih subjekata.

Iz navedenog proizilazi da ukoliko nakon smrti preduzetnika, u roku od 30 dana, naslednik, odnosno član njegovog porodičnog domaćinstva obavesti registar da nastavlja obavljanje delatnosti, u tom slučaju on ulazi u prava i obaveze koje je imao prethodni preduzetnik, pa samim tim odgovara i za sve obaveze preduzetnika, svojom imovinom. U tom slučaju nema prekida kontinuiteta obavljanja delatnosti od strane naslednika, pa je lice - novi preduzetnik odgovoran za sva prava i obaveze prethodnog preduzetnika.

Ukoliko se ne nastavi sa obavljanjem preduzetničke delatnosti, na navedeni način, već se registruje prestanak - brisanje preduzetnika, u tom slučaju naslednici preduzetnika odgovaraju za obaveze preduzetnika po pravilima nasleđa, do visine naslednog dela. ${ }^{6}$

5 Iz presude Apelacionog suda u Novom Sadu, Gž. 615/2012 od 18.10.2012. godine, ParagrafLex.

6 Privredni apelacioni sud - Pitanja i odgovori - radni materijal - sa XX savetovanja privrednih sudova Republike Srbije, Zlatibor, septembar 2012. godine, www.sudskapraksa.com. 


\section{REZIME}

Odgovornost preduzetnika za obaveze nastale u vezi sa obavljanjem delatnosti je lična, neposredna i neograničena, bez mogućnosti njenog ograničenja i ista ne prestaje brisanjem preduzetnika iz registra. Supružnici preduzetnika solidarno odgovaraju za obaveze lica koji je istupalo u svojstvu preduzetnika, ukoliko se njihovo zajedničko domaćinstvo izdržavalo od prihoda ostvarenih preduzetničkom delatnošću. Poreskim propisima je predviđena posebna odgovornost i članova porodičnog domaćinstva. Za porez na prihode od samostalne delatnosti jemče supsidijarno svojom imovinom svi punoletni članovi domaćinstva obveznika koji u momentu nastanka obaveze čine domaćinstvo obveznika. U slučaju smrti preduzetnika ako naslednik, shodno pozitivnim propisima, nastavi obavljanje delatnosti nema prekida kontinuiteta obavljanja delatnosti pa novi preduzetnik odgovara za sve obaveze prethodnog preduzetnika. Brisanjem preduzetnika usled smrti naslednici odgovaraju za obaveze preduzetnika do visine nasleđenog dela, po prvilima naslednog prava.

\section{LITERATURA}

Babić, I. (2011). Građansko pravo, Knjiga 1. Uvod u građansko pravo, Beograd: Službeni glasnik; Novi Sad: Fakultet za evropske pravno-političke studije.

Babić, I. (2008). Leksikon obligacionog prava. Beograd: Službeni glasnik.

Carić, S., Vitez, M., \& Veselinović P. J. (2006). Privredno pravo. Novi Sad: Privredna akademija,

Chambers of Commerce Euregio Meuse-Rhine - CCEMR. (2014). Database of legal entities. Preuzeto 3. oktobra 2015. sa http:// www.euregiochambers.eu/legal-enities/germany/sole-proprietorship.html
Clark, J.O.E. (2001). Dictionary of international accounting terms. Canterbury: Financial World.

Cohen, W.A. (2006). Entrepreneur and Small Business Problem Solver. New York: John Wiley \& Sons.

Commercial Register from Germany - CRG. (2014). Legal forms in Germany. Preuzeto 3. oktobra 2015. sa http://www.commercial-register.com/legalformsgermany.html

Dabić, Lj. (2008). Pojmovno određenje i svojstva slobodnih profesija. Pravni život, br. 12/2008,

Gruenden. (2015). Step by step to your own company, Legal structure - sole proprietorship. Preuzeto 3. oktobra 2015. sa http://www.gruenden.ch/en/founding-process/preparation/legal-forms/sole-propretorship

Marković, V. (2014). Imovina, neto imovina (kapital) i osnovni kapital privrednog društva. Zbornik radova međunarodne naučne konferencije „Finansijsko izveštavanje u funkciji korporativnog upravljanja“. Beograd: Univerzitet Singidunum.

Masoom, K. (2013). The Entrepreneur's Dictionary of Business and Financial Terms. Partridge India,

Moye, J. (2004). The Law of Business Organizations. Cengage Learning.

Paund, R. (2000). Jurisprudencija, knjiga II. Beogad: Službeni list SRJ; Podgorica: CID.

Stefanović, Z. (2014). Pravni položaj i aktuelna pitanja obavljanja delatnosti u statusu preduzetnika. Pravni instruktor broj 68/2014, stručni komentar ParagafLex.

Spadaccini, M. (2007). Business Structures: Forming a Corporation, LLC, Partnership, Or Sole Proprietorship. Irvine, CA: Entrepreneur Press.

Vasiljević, M. (2008). Kompanijsko i trgovinsko pravo. Beograd: Pravni fakultet Univerziteta u Beogradu; Beograd: Službeni glasnik.

\section{PROPERTY AND RESPONSIBILITY FOR ENTREPRENEUR'S LIABILITIES}

\begin{abstract}
:
An entrepreneur is a competent, natural person who performs activities in order to achieve greater income and as such is registered in accordance with the Law on Registration of Business Entities. The Law on Business Entities does not specify what makes the entrepreneur's property. The concept of property is governed by the civil law regulations. The property is a collection of subjective property rights of a single person. The property consists of real rights, intellectual property rights (copyright and industrial property rights), personality rights (if expressed in the form of property) and obligation rights (except for those that cannot be expressed in monetary terms). The entrepreneur is responsible for all liabilities incurred in relation to his/her business activities and uses all its assets as a guarantee, including the assets acquired in connection with related activities. The responsibility for liabilities arising in connection with their activities is personal, immediate and unrestricted, without any possibility of its limitations and it does not cease by deletion of entrepreneurs from the registry. In practice, responsibility of spouses for entrepreneur's liabilities, responsibilities of household members, arises as a controversial issue, in case of change of a legal form into a company, in case of death or loss of legal capacity. Based on the theory and jurisprudence and comparative-legal solutions, the author analyzes the personal responsibility of entrepreneurs, but also the responsibility of spouses and household members for the liabilities of entrepreneurs, entrepreneur's responsibility in case of change of the legal form, as well as the responsibility of heirs in case of death of the entrepreneur or deprivation of legal capacity for the purpose of clarifying disputes.
\end{abstract}

\section{Key words:}

entrepreneur, property of entrepreneur, responsibility for liabilities. 